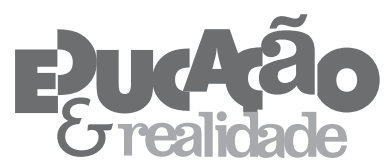

\title{
A Hegemonia do Tempo Escolar
}

\author{
Nuno Vieira' \\ 'Universidade Lusófona de Humanidades e Tecnologias, Lisboa - Portugal
}

RESUMO - A Hegemonia do Tempo Escolar. As concepções de tempo e a relação que o Homem com ele estabelece têm evoluído no sentido de afirmá-lo como um elemento-chave da civilização. A evolução dos mecanismos horários e dos sincronismos contribuiu para que a escola seja regulada pelo relógio. Mesmo os ritmos circadianos tendem a ser regulados por entidades externas, como os tempos escolares. Está inscrito no currículo oculto da escola o respeito por determinadas regras e valores temporais, ou seja, a escola tem a tarefa de ensinar os alunos a viverem em função de ritmos (temporais) impostos pelas instituições. O tempo tem assumido uma crescente importância na sociedade, onde a escola desempenha um papel importante na transmissão de regras e valores, constituindo-se um elemento da sua gramática. É um elemento estrutural na escola e estruturante na sociedade. No presente, o tempo regula a atividade humana de forma doutrinal, sem ser questionado.

Palavras-chave: Tempo. Sincronismo. Tempo Escolar. Opressão.

ABSTRACT - The Hegemony of School Time. Time conceptions and the relationship that humankind establishes with it became a key element of civilization. The evolution of time mechanisms and synchronization methods has contributed to the school regulation being dictated by the clock. Even circadian rhythms tend to be regulated by outside agencies such as the school times. The respect for certain rules and time values is included in the school's hidden curriculum, that is, the school has to teach students to live according to (temporal) rhythms imposed by the institutions. Time has assumed an increasing importance in society, where school has played an important role in the transmission of rules and values, becoming an element of the grammar of schooling. It is a structural element in schools and structuring in society. Presently, time regulates the human activity in a doctrinal way, without being questioned.

Keywords: Time. Synchronism. School Time. Oppression.

Educação \& Realidade, Porto Alegre, v. 41, n. 2, p. 515-531, abr./jun. 2016 515 http://dx.doi.org/10.1590/2175-623646446 


\section{Introdução}

You may delay, but time will not (Benjamin Franklin).

O conceito de tempo acompanha todo o percurso biológico e social da humanidade tornando-se, a par de tudo o que rodeia o homem, uma parte do ambiente. Estabelece ritmos de vida, define atitudes e influencia comportamento, tanto em nível individual, como em nível da ação social. Desde a antiguidade que, nas mais diversas abordagens, o tempo tem sido objeto de análise filosófica e tecnológica, mas foram os relógios de pêndulo, de Galileu, que o tornaram num pilar essencial para as ciências nomotéticas, tomando um lugar central nas teorias da mecânica clássica e da relatividade. O génio de Galileu permitiu-lhe construir mecanismos para contar o tempo ${ }^{1}$ com o rigor e a precisão suficientes (Glennie; Thrift, 2009) para levar a cabo as experiências fundadoras da mecânica. Embora não o tenha verdadeiramente caracterizado, Galileu estabeleceu uma relação geométrica entre as noções de espaço e de tempo, definindo movimento regular ou uniforme como aquele em que são percorridos espaços iguais, em tempos iguais (Klein, 2007).

Uma vez dominado o conhecimento científico e tecnológico para a contagem do tempo, decorreram dois séculos para se assistir à efetivação do sincronismo horário, primeiro a nível local, generalizando-se, em poucos anos, para um nível global. Atendendo a que o mundo geopolítico está cada vez mais interdependente, no campo social as concepções de tempo assistem a uma evolução particularmente sensível, onde um pensamento linear não se afigura como uma forma eficaz de compreender as múltiplas relações do tempo, lugar e espaço, bem patente nas teorias da relatividade. Estas relações expõem um tempo mesclado com o espaço, evidenciando uma não linearidade do curso do tempo. Assim, a busca por uma definição do conceito de tempo já perdeu o estatuto de objeto de estudo de uma ciência, que se limita a examiná-lo numa vertente particular, para passar a ser um conceito multirreferenciado, em variadas e, sobretudo, diversificadas áreas do conhecimento.

Uma teoria universal do tempo multirreferenciada não assenta num princípio de eliminar a singularidade de cada área do conhecimento que o estuda, pelo contrário, "[...] tem de satisfazer uma alargada variedade de especificações, porque o tempo envolve o nosso pensamento e a nossa experiência em todas as dimensões em que nos inserimos no mundo. Daqui se depreende que o estudo do tempo tem de assentar em perspetivas multidisciplinares" (Fraser, 1981, p. xxxvi). A concepção de tempo orienta-se no sentido de combater o isolamento, traçando caminhos que facultem a interação entre saberes, e desta forma elucidar as diversificadas compreensões do tempo. Estes caminhos, não só permitem um entendimento do tempo mais abrangente, como 
também podem desvendar as relações espaço-tempo que, com os avanços tecnológicos, assumem um papel primordial na orientação e mobilidade no espaço físico. "Uma teoria universal do tempo não se destina a eliminar as particularidades das áreas do conhecimento que para ela contribuem, mas a procurar perspetivas diversificadas que eliminem seu isolamento a que estas áreas estão votadas" (Fraser, 1981, p. xxvii).

As nossas concepções de tempo, e a forma como condicionamos a vida em sociedade ao espaço e ao tempo, conduziram a que tenhamos deixado de respeitar os ritmos circadianos. Não comemos ou descansamos quando o corpo pede, uma vez que estamos condicionados pelos sincronismos impostos pelo ritmo social, pela hora de levantar, hora de almoçar ou de jantar, sempre ajustados às imposições globais. Começamos a trabalhar quando do sinal horário, paramos com idêntico sinal. Comemos em sincronia, sociabilizamos em sincronia, partilhamos momentos de lazer em sincronia. A ação social de um indivíduo está, em diferentes graus de intensidade, condicionada por reguladores tão diversificados como os astros, os pêndulos, o impulso elétrico de um cristal, o decaimento radioativo de um elemento químico, ou seja, por qualquer fenómeno de periodicidade extra-humana. A escola ensina-nos a subjugar-nos aos relógios desde o primeiro dia em que entramos num sistema escolarizado, independentemente da idade. Lá aprendemos a importância da pontualidade, da necessidade de cumprir os tempos de realização de tarefas, havendo penalizações para os incumpridores.

\section{O Sincronismo Horário}

Desde muito cedo que a doutrina religiosa impôs regras que se traduziram na sincronização da atividade religiosa. Os templos ocidentais criaram mecanismos para regular os ritmos dos frades e impor-lhes atividades sincrónicas, atribuindo ao tempo um poder doutrinal, onde a "[...] regra impunha a sua disciplina de ferro, ritmando a vida monástica de uma maneira que deixava pouco espaço para a fantasia" (Klein, 2007). No séc. VII a bula do papa Sabiano impunha que os sinos tocassem sete vezes a cada período de vinte e quatro horas, para marcar as sete horas canónicas (Klein, 2007)². O martelo do sino era acionado por uma clepsidra que, quando o reservatório de recolha da água atingia um determinado peso, acionava o mecanismo do sino. Como todos os sistemas de contagem da passagem do tempo que recorriam à água como marcador do passo, estava condicionado pelos caprichos da meteorologia que, por vezes e em determinados locais, congelava a água, inviabilizando a marcação das respetivas horas canónicas. Esta regra, imposta nos mosteiros, difundiu-se rapidamente pelas cidades, que adotaram os primeiros mecanismos de contagem do tempo com o poder de regular um comportamento social. Ou melhor, atribuíram a um mecanismo o poder de medir durações entre dois acontecimentos. Quando o sino se fazia ouvir, era hora de rezar, independentemente dos afazeres. No séc. XIV os relógios “[...] tocavam as horas nas cidades, 
A Hegemonia do Tempo Escolar

sincronizando as atividades humanas e sociais, inaugurando uma regularidade até então desconhecida na vida dos artesãos e mercadores" (Klein, 2007, p. 16). Durante a época medieval, determinados momentos do dia eram marcados por toques, muito antes da invenção dos relógios mecânicos, que se destinavam tanto à população em geral, como para determinados grupos da sociedade. Diferentes sinais, no número de toques, na duração, na intensidade, na localização do sino, destinavam-se a diferentes finalidades ou grupos, gerando nas grandes cidades o que "[...] foi adequadamente descrito como o caos acústico" (Glennie; Thrift, 2009, p. 38). Landes considera mesmo que não haverá outro artefacto humano que tenha “[...] desempenhado um papel tão crítico na modelação do caráter da vida e do trabalho como os relógios" (Landes, 2009, p. 34 ), como atualmente o relógio da escola modela o trabalho dos alunos, ensinando-os, treinando-os diríamos, a respeitar estas regras temporais, impondo penalizações quando os incumprem.

Com o desenrolar da atividade mercantil, a cada vez maior capacidade de movimentação no globo, criou novas oportunidades de comércio que, consequentemente, conduziram à necessidade de uniformização da métrica, que se foi acentuando com o avanço da industrialização. Tornou-se evidente que a diversidade métrica constituía um entrave às relações comerciais. Toda a definição da métrica, encetada pelos eminentes pensadores da Academia Francesa que culminou na Convenção do Metro, foi marcada por uma racionalidade científica e filosófica, da qual a referência ao tempo não se diferenciou. Contrastando com este racionalismo francês, a American Metrological Society, abordou a metrologia de uma forma pragmática, uniformizando os sistemas e tornando-os interconvertíveis. As regras relativas a toda a métrica foram rapidamente implementadas nas escolas e universidades, enraizando-se a sua prática no quotidiano e transferindo-as para o domínio público. No entanto, em 1879, Cleveland Abbe, presidente da Comissão para o Tempo Coordenado, da American Metrological Society, constatara que o quotidiano das pessoas era regido por uma métrica temporal aferida pelos relógios das redes de caminhos-de-ferro, relegando para um plano secundário as horas astronómicas locais (Galison, 2005). Para a Comissão era evidente que em termos práticos as populações estavam, direta ou indiretamente, ligadas às locomotivas e, consequentemente, pouco ou nada as ligava às estrelas. Assim, Abbe defendeu que a uniformização do tempo deveria dar relevo à hora imposta pelas redes ferroviárias, na mesma medida em que consideraria o tempo astronómico, sob pena das medidas que se viessem a tomar, no sentido da uniformização do tempo, se tornarem inconsequentes para o quotidiano das populações.

O pragmatismo americano permitiu uma abordagem multidisciplinar ao tempo, que envolveu uma grande diversidade de entidades, contribuindo de uma forma mais ou menos direta, que mostravam ter interesse na sua uniformização. Na última década do séc. XIX “[...] a

518 Educação \& Realidade, Porto Alegre, v. 41, n. 2, p. 515-531, abr./jun. 2016. 
América distinguia-se pela distribuição industrial das horas e a Inglaterra pela sua rede de cabos submarinos, que dominava o mundo" (Galison, 2005), dado que o sinal horário emitido pelo relógio-mestre passara a ser distribuído pelas redes telegráficas, espalhadas um pouco por todo o mundo ocidental. De uma forma natural as possessões inglesas da América do Norte, associadas à rede ferroviária dos Estados Unidos, acordaram em estabelecer Greenwich como o tempo zero ou, por outras palavras, a origem da contagem do tempo.

A 19 de Outubro de 1881 as linhas de caminho-de-ferro americanas acordaram em abolir a referência horária da cidade de origem da locomotiva, passando todas a reger-se por um sistema horário único, com três fusos para todo o território dos EUA, aceitando, igualmente, a proposta de Fleming de manter o meridiano de Greenwich como o meridiano zero. Rapidamente se constatou que a implementação da hora oficial convencionada pelos caminhos-de-ferro, em detrimento da hora local, não representava constrangimentos para o quotidiano das populações, uma vez que na maioria dos casos apenas diferia em alguns minutos. Assim, nos dois anos que se seguiram, o tempo convencionado pelos caminhos-de-ferro foi sendo sucessivamente adotado pelas cidades americanas, anulando as respetivas horas locais.

Entretanto a Europa continuava a encarar a questão numa perspetiva inteiramente diferente. A academia e os observatórios não abordavam o tempo, como geralmente não abordavam qualquer outro tema de carácter eminentemente científico, numa perspetiva comercial ou económica, ainda imperavam os ideais do Iluminismo. Se a Natureza definira a primeira latitude - o equador - não definira a primeira longitude, e sempre que o zero de um sistema métrico não está naturalmente definido, resta o acordo entre os pares para o convencionar. Para tal, realizou-se em 1884, em Washington D.C., The International Meridian Conference, na qual se fizeram representar 25 nações pelos seus mais eminentes cientistas e políticos.

Uma vez que o sincronismo horário estava condicionado pela comunicação por telégrafo, era fundamental que o meridiano zero passasse por um observatório que, à época, estivesse inteiramente eletrificado. Perante a evidência de que a maioria das cartas marítimas mercantes, da época, estarem construídas tendo por base o meridiano de Greenwich, este apresentava-se como a opção mais consensual, sendo também a mais vantajosa em termos comerciais. De facto, em apenas 10 anos, todo o mundo ligado por trocas comerciais, se adaptara ao novo sistema horário, apenas resistindo à mudança a Ocidente, França, Espanha e Portugal, cuja hora oficial apresentava um adiantamento de apenas de 9min 27s relativamente à hora oficial de Greenwich (Galison, 2005).

Em Agosto de 1904 a marinha americana emitia sinais rádio de curto alcance, a partir de Cabo Cod (Massachusetts) e de Norfolk (Virgínia), para sincronizar os relógios da sua frota (Galison, 2005). No mesmo 
ano, a França e a Suíça faziam ensaios a partir dos respetivos observatórios astronómicos, para viabilizarem sistemas que cumprissem os mesmos objetivos. Contrariamente à precisão conseguida através das redes de telégrafos, limitada à ordem do quarto de segundo, este novo meio de comunicação permitia sincronizar relógios com uma precisão da ordem da centésima de segundo, uma vez que a velocidade de propagação do sinal pelo ar é próxima da velocidade da luz.

Rapidamente se percebeu que, quanto mais alto estivessem as antenas emissoras, maior seria o alcance do sinal, pelo que, em Maio de 1908, começou a ser emitido um sinal horário, via rádio, do topo da Torre Eiffel, que permitia a determinação exata da longitude em qualquer local onde fosse recebido. Estes sinais-rádio, reguladores do tempo e mestres do sincronismo, eram percetíveis nos continentes americano, asiático e africano. Para a França, a emissão do sinal horário a partir da Torre Eiffel representou retomar a charneira na definição dos sistemas métricos (como já fizera com o comprimento e com o volume), bastando-lhe, a 9 de Março de 1911, aceitar a hora de Greenwich como hora oficial e atrasar os seus relógios os nove minutos e vinte e sete segundos que os diferenciavam. Mil Novecentos e Doze, foi o ano da consagração francesa na marcação do tempo, com a emissão do sinal, a partir da torre Eiffel que possibilitava definir a longitude em todo o Planeta. Foi, sem dúvida, um tributo a Poincarré, no ano da sua morte.

Todo o séc. XX foi marcado pela evolução do conhecimento científico nos mais diversos campos do conhecimento, com repercussões significativas na tecnologia que deu passos largos, impulsionando e sendo impulsionada pela ciência numa espiral de produção de conhecimento. A contagem do tempo e a sincronia dos relógios acompanharam esta revolução técnico-científica.

No final do séc. XX, os relógios apresentam uma precisão que no início do século seria inimaginável, mesmo para os mais crédulos. Os cristais de quartzo que haviam passado a desempenhar a função de marcar o passo do mecanismo dos relógios, em detrimento do pêndulo, seriam substituídos pelos ainda mais precisos relógios atómicos, com o decaimento do Césio a substituir a função dos cristais de quartzo, hoje usados no sistema GPS (Global Positioning Sattelite). Estes relógios apresentam uma exatidão de 50 bilionésimos de segundo por dia (Galison, 2005). E, uma vez que comparativamente aos relógios atómicos, o Tempo das Efemérides ${ }^{3}$ é variável, oscila na ordem do 1 segundo por ano, conclui-se que nem este sistema de contagem do tempo, presente em toda a história da humanidade e identificável em todas as civilizações, é tão preciso como a contagem do tempo utilizado no sistema GPS.

A conjunção dos conceitos filosóficos de tempo e espaço relativos, com o conhecimento científico e tecnológico, criou um sistema mais regular que o próprio movimento de translação terrestre, permitindo determinar a velocidade de deriva de qualquer corpo no planeta: um carro, uma corrente marítima, uma montanha, uma ilha, ou até mesmo 
uma placa tectónica continental. Criou, ainda, uma perspetiva dinâmica do planeta, onde nada está fixo e tudo se move, dando um novo sentido ao conceito de relatividade proposto por Galileu. Este sistema, por ser mais regular que o próprio planeta, acaba por impor acertos de calendário periódicos, como o verificado no ano de 2008, em que para (re)acertar a duração medida pelos relógios atómicos com a duração das Efemérides, acrescentou-se 1s ao último minuto do ano.

\section{O Tempo Absoluto e as Temporalidades}

O homem sempre se regulou pelas Efemérides e recorreu a artefactos, como os relógios de Sol, as ampulhetas ou as clepsidras, para marcar a passagem do tempo. A evolução tecnológica dos artefactos decorreu num período temporal que não difere muito do da história da humanidade. Mas, como vimos, o sincronismo horário entre relógios à distância, apenas se iniciou no final do séc. XIX e, em cem anos assistiu-se a uma assinalável evolução, passando de uma eficácia da ordem do minuto para uma ínfima fração de segundo, correspondendo ao aumento da precisão e a exatidão a um expoente inimaginável, até para um visionário, como Júlio Verne, ou para o génio de Einstein, o cientista filósofo, como Galison (2005) o apelidou.

As pessoas têm os sentidos, olfato, tato, paladar e audição mais ou menos desenvolvidos e, como é sabido, estes também se treinam e educam. Podemos comparar a nossa perceção de tempo aos sentidos, considerando haver um sentido que mede a rapidez do tempo. Contrariamente às teses empiristas de David Hume, entre outros, defensoras da ideia de que o conhecimento se reduzia ao que era experienciado diretamente pelos sentidos, pois estes não nos enganariam, o tato, o olfato, a audição enganam-nos, tal como nos engana a nossa perceção da rapidez do tempo.

O ritmo biológico do ser humano não se substitui aos relógios e a perceção da rapidez temporal, ou seja, a noção do tempo que o próprio tempo demora a passar é condicionada por um conjunto de fatores que são independentes dos mecanismos de medição temporais, tanto das efemérides, como atómicas. Esta rapidez pode ser condicionada por fatores pessoais e sociais, muitas vezes relacionados com a intensidade em que se vive o período temporal, ou pelo significado dos acontecimentos que estão prestes ou a desenrolar-se (Klein, 2007). Sem os relógios, a nossa apreciação do tempo, a par da duração, difere significativamente do que experienciamos quando o cronos regula o quotidiano. Os ciclos biológicos dos organismos vivos, e naturalmente do Homem, têm ritmos circadianos de aproximadamente vinte e quatro horas, mesmo na ausência de contagem do tempo, seja por fotoperiodismo ou por qualquer outro fator, o homem mantém os ciclos biológicos. Pessoas sujeitas a fotoperíodos cronometrados de $27 \mathrm{~h}$ mantêm muito dos seus ritmos circadianos em períodos próximos de $24 \mathrm{~h}$ (Hamner, 1981). No entanto, facilmente se constata que a generalidade dos ritmos circadianos dos

Educação \& Realidade, Porto Alegre, v. 41, n. 2, p. 515-531, abr./jun. 2016. 521 
A Hegemonia do Tempo Escolar

organismos vivos está regulada pelo período de luz e, em escala muito menos significativa pelas variações térmicas, por variações barométricas, ou por ritmos alimentares (Cloudsley-Thompson, 1981). Inclusive, quando o homem se sujeita a condições de luminosidade constantes, o organismo "[...] faz reajustes permanentes, numa busca inútil do fotoperíodo, num processo conhecido como autophasing" (Cloudsley-Thompson, 1981, p. 304).

Para Nowotny “[...] o tempo social remete para a experiência do tempo inter-subjetivo através das relações sociais, tanto no plano comportamental como simbólico" (Nowotny, 1992, p. 425) mas, a própria autora refere que nesta definição falta uma referência à pluralidade dos tempos sociais. É, hoje, mais ou menos consensual que “[...] diferentes sociedades produzem qualitativamente diferentes concepções de espaço e de tempo" (Harvey, 1996, p. 210). A par dos conhecimentos construídos pelas ciências, nomotéticas ou ideográficas, estão, com a mesma legitimidade, os conhecimentos produzidos pelos grupos sociais e étnicos. São estes que determinam as relações individuais e coletivas que se estabelecem com o tempo, perfilando-o como um agente sujeito a juízos e critérios de racionalidade. No nosso quotidiano facilmente nos deparamos, consciente ou inconscientemente, com questões em torno do tempo: o que é o tempo? Como é que o entendemos? O que com ele, e dele, fazemos? Como o gerimos?

Apesar dos avanços das ciências sociais na área das temporalides, a escola continua a dar-nos uma perspetiva de tempo, absoluto e universal, com a mesma velocidade em qualquer parte do Universo (Klein, 2007) e, sobretudo, não deixa o campo aberto para outras considerações menos deterministas. Daqui decorre que, em regra, não se levantem reservas quando se trata de regular a atividade social a partir de relógios sincronizados, nem se questione a veracidade de considerar que os relógios uma vez sincronizados, e independentemente das condições a que estão sujeitos, mantenham esta característica para todo o sempre. Ou, por outras palavras, considera-se que o sincronismo é absoluto, universalizando não apenas a concepção de tempo das Efemérides, como a newtoniana de tempo, para quem o tempo subjetivo é uma medida que os nossos sentidos fazem desse tempo absoluto, que flui uniformemente, portanto, deverá também ele, fluir uniformemente, independentemente da forma como o vivenciamos (Pöppel, 1985). Daqui se depreende que observadores que sincronizem os seus relógios, caso não estejam sujeitos a qualquer aceleração e não sofram nenhum efeito gravitacional mútuo, vêm-nos manterem-se regulados para toda a evolução cósmica (Klein, 2007). No entanto, a concepção social dos tempos difere da perspetiva determinista de tempo, característica das ciências nomotéticas, na forma como escoa, enquanto que para estas podemos estabelecer uma velocidade temporal contínua, os tempos sociais apresentam-se de uma forma muito mais complexa, com uma rapidez variável.

522 Educação \& Realidade, Porto Alegre, v. 41, n. 2, p. 515-531, abr./jun. 2016. 
Tanto assim é que o homem sempre sentiu necessidade de medir o tempo das Efemérides, para regular ritmos e hábitos sociais, que culmina na centralidade que o tempo atualmente ocupa nas sociedades, como vimos, resultado da evolução tecnológica nos seus métodos de contagem e, sobretudo, na capacidade de sincronização que foi gradualmente transformando a atividade social, até que atualmente ocupa um papel, com tanto de oculto como de central.

\section{As Concepções Temporais Inscritas no Currículo Oculto da Escola}

A dependência social do relógio, onde a própria noção de posição e de espaço se subjugou ao tempo, tem conduzido as sociedades ocidentais num processo de dependência do sincronismo, ao ponto de, numa perspetiva freireana (Freire, 1987) lhe ter sido dada a capacidade de exercer uma ação opressora sobre o indivíduo. A sucessão de acontecimentos e solicitações que ocorrem no quotidiano tem vindo a ocupar, paulatinamente, um lugar central na ação social, condicionando sucessivas tomadas de decisão, ou, em situações limite, obrigando à execução de ações sem uma prévia, ou maturada, análise, sem a devida reflexão. O sincronismo define os limites temporais, ou seja, define a duração que dispomos para realizar cenários ou ponderar ações. Daqui resultam atos não poucas vezes precipitados, de consequências mais ou menos gravosas, mensageiros de maior ou menor arrependimento. Isto sucede, não porque o provérbio português o tempo é bom conselheiro tenha perdido a sua validade, apenas não dispomos da possibilidade de nos regularmos individualmente no tempo. O tempo que dispomos para aplicarmos os nossos conhecimentos está limitado pela sucessão de acontecimentos exigindo a sua otimização. Esta otimização será tanto mais eficaz quanto melhor for a capacidade que dispomos para: lermos o mundo, interpretarmos e analisarmos estes códigos - literacia; racionalizarmos esta informação - materacia; para, então, decidirmos como atuar - tecnoracia. Literacia Materacia e Tecnoracia constituem o conhecimento trivium (Vieira, 2013) do indivíduo, cuja definição tem por base o currículo trivium proposto por D'Ambrósio (D'ambrosio, 1999; 2001). O conhecimento trivium poderá permitir ao indivíduo otimizar o tempo de ação, tornando-se tanto mais significativo quanto menos tempo se dispuser para se atuar. A escola começa por ensinar regras temporais, como a já referida pontualidade, ou a necessidade de realizar as tarefas de forma segmentada no tempo, em intervalos temporais pré-estabelecidos, rígidos. A escola estruturada em saberes segmentados em disciplinas, por sua vez compartimentadas em blocos temporais pré-definidos treina os alunos em processos de otimização do tempo. Este processo de aquisição de conhecimento trivium é particularmente relevante em momentos formais de avaliação, onde a limitação temporal tem particular importância, pois os alunos devem mostrar o que sabem dentro do intervalo de tempo que lhes é dado para 
o fazerem. Ou seja, não basta saberem, têm de conseguir mostrar que sabem no tempo que lhes é concedido. Assim, o próprio tempo tem uma capacidade avaliadora, está nele a capacidade de distinguir alunos que hipoteticamente tenham o mesmo nível de conhecimento: será melhor aluno o que o demonstrar num intervalo de tempo idealizado para a realização da tarefa.

Assim, as concepções subordinadas a arquétipos como o tempo é dinheiro são desvendadas. Expressões linguísticas como, o tempo voa, não tenho tempo, tenho de arranjar tempo para..., são expressões proferidas e ouvidas frequentemente, com cada vez mais propensão, que ilustram a relação de dependência que um indivíduo estabelece com o tempo. Uma assimilação do significado destas e outras expressões em torno do conceito de tempo, a cada momento que são referidas, poderá configurar-se como um processo para uma compreensão da relação que o indivíduo estabelece com o tempo.

Esta racionalidade social relativa ao tempo repercute-se nas estruturas escolares não permitindo “[...] pensar o tempo sem tomar em consideração os processos da sua medição e das formas como é dividido" (Adam, 2004, p. 103), evidente na lógica da constituição dos horários em ciclos temporais. Whitrow (2003, p. 9) lembra que já no séc. XIV, nas escolas italianas o tempo era tomado como algo com valor, que fluía de um modo contínuo e uniforme.

Já Foucault (1977) apresenta-nos uma abordagem ao tempo escolar equiparada à lógica dos tempos nas instituições militares, encontrando equivalência entre as regras e os princípios praticados nas escolas e nos quartéis. Em ambas as instituições - escola e quartéis - a duração das atividades é dividida em “[...] segmentos, sucessivos e paralelos, dos quais cada um deve chegar a um termo específico" (Foucault, 1977, p. 143). Ou seja, uma atividade, que tanto pode ser uma aula de determinado conteúdo escolar ou a aprendizagem de um procedimento militar, no quartel está dividida em períodos temporais, ajustados, cada um, a uma finalidade. Enquanto nos quartéis são definidas horas para manipular armas ou para aprender e treinar a marcha, nos sistemas de ensino, designadamente os ocidentais, as unidades curriculares são hierarquizadas por diferentes níveis de relevância, com correspondência direta no número de horas que o currículo estipula para cada uma.

Na lógica da organização das escolas e dos quartéis, ilustrada por Foucault, só se passa para o segmento seguinte (que, nas escolas pode ser um semestre, um ano letivo, as fases do ensino fundamental ou o ensino médio) quando o precedente está já adquirido pelo aprendente - aluno ou recruta - sendo a lógica "[...] decompor o tempo em sequências, separadas e ajustadas e organizadas seguindo um esquema analítico" (Foucault, 1977, p. 143), partem do mais simples para o mais complexo, de forma progressiva, aumentando o grau de complexidade à medida que se vai obtendo aprovação nos segmentos anteriores. Para cada segmento deve ser fixado um "[...] termo marcado por uma prova 
que tem a tríplice função de indicar se o indivíduo atingiu o nível estatutário, de garantir que a sua aprendizagem está em conformidade com a dos outros, e diferenciar as capacidades de cada indivíduo" (Foucault, 1977, p. 143).

Na sua abordagem biossocial, ou sócio-biológica, Foucault (1977) releva que, desde a criação das primeiras instituições escolares, o tempo foi administrado visando a regulação/disciplina dos corpos e através desta dos espíritos, treinando-os para ritmos de trabalho distintos dos circadianos, até então associados ao tempo das efemérides, e que regulavam a atividade humana, nomeadamente o dia natural ${ }^{4}$. O horário escolar rígido ensina, então, no aluno a respeitar um ritmo de trabalho que em muitos casos contraria os seus próprios ritmos circadianos, no que Gimeno Sacristán (2008, p. 26) classifica como tempo biológico ou biopsíquico, numa tentativa de homogeneização da sociedade também no que respeita a ritmos e hábitos de trabalho. Esta normalização social continua a seguir os princípios da regulação horária muito cedo impostos pela doutrina religiosa, como já tivemos oportunidade de referir, mas que se acentuou particularmente com a revolução industrial. "Havia que organizar e disciplinar a grande heterogeneidade, pôr o espaço escolar a funcionar como uma máquina de ensinar, organizando uma nova economia do tempo de aprendizagem” (Brites, 2007, p. 173).

A escola incute nos alunos uma noção de tempo que é considerado como um bem, a utilizar de forma racional e produtiva, já que na vida ativa “[...] todas as práticas temporais da indústria, apesar da sua diversidade, dependem do tempo criado pelo desígnio humano, isto é, do tempo descontextualizado e quantificável por um relógio. Assente no princípio do tempo cronológico, o tempo económico pode florescer e estabelecer o paralelismo entre tempo e dinheiro" (Adam, 2004, p. 73). A escola, então, contribui significativamente para a generalização desta concepção de tempo à escala global. A relação que a sociedade estabelece com o tempo sempre foi, e continua a ser, crucial para as organizações educativas e para a vida de todos os que a constituem - alunos, professores, funcionários. Também influencia, e como, outros não tão diretamente envolvidos, as famílias, as instituições, algumas áreas do comércio. Consideramos que será aqui, nesta dimensão, que o tempo da escola se distancia do tempo do quartel.

Mas, retomemos o que temos vindo a tentar ilustrar, a escola está incumbida de treinar os alunos para as regras temporais que a sociedade impõe. Assim, as crianças são, desde tenra idade, subjugadas aos ritmos determinados pela escola, “[...] permitindo ajustar o relógio biológico dos sujeitos escolarizados aos códigos em que se formaliza o tempo da educação" (Benedito, 2008, p. 35). Este é indubitavelmente, no nosso entender, um elemento primordial do currículo oculto (Tyack; Cuban, 1995) da instituição escolar dos nossos dias. Mas o tempo também é fundamental para a escola enquanto instituição, dado que "[...] constitui um dos elementos estruturais e estruturantes na cultura de escola” 
(Benedito, 2008, p. 33). Estrutural, porque toda a organização escolar está concebida e ordenada em torno dos horários, essenciais ao seu funcionamento. Estruturante, porque se relaciona com todas as estruturas sociais existentes em torno da escola e que condicionam as atividades desenvolvidas no seu interior (organização de espaços, momentos de sociabilização, desenvolvimento dos curricula, o que é ensinado, quando e com que duração) ${ }^{5}$. O horário escolar é um fiel registo do trabalho desenvolvido na escola, tanto no que diz respeito aos alunos como aos professores. "Horários, calendários, horas de trabalho, tempo de recreio, o fim das aulas, são referências fundamentais no pensamento tecnificado moderno acerca do tempo em educação" (Gimeno Sacristán, 2008, p. 19). Cada disciplina dispõe de X horas, repetidas em ciclos semanais, durante Y meses, no decurso de Z anos. Esta segmentação do tempo, vigente no ensino em pluridocência, forja a relação que o aluno estabelece com o tempo, sendo também, desse ponto de vista, um agente delineador e segmentador das ações ocupacionais e sociais.

Gimeno Sacristán (2008) salienta que o tempo da escola, regulado, organiza a ação individual e coletiva, tem capacidade para impor limites e estabelecer regras sociais, chegando mesmo a posicionar-se como um agente habilitado a classificar os sujeitos, posicionando-as na "[...] fronteira entre a normalidade e a anormalidade" (Gimeno Sacristán, 2008, p. 21). E avança um conjunto de exemplos relacionados com a estrutura do sistema escolar, particularmente com o funcionamento das escolas: o toque da campainha da escola tem um poder educador, na medida em que tem a capacidade de uniformizar os ritmos das crianças e dos jovens; a consulta sistemática do relógio, por parte dos alunos, durante as aulas, indicia que este tempo lhes é imposto e que não o entendem como seu; o aluno que se atrasa frequentemente na realização das tarefas sugeridas pelo professor, rapidamente é inserido na categoria de alunos lentos; os que se atrasam sistematicamente estão num desfasamento horário relativamente ao tempo físico dos relógios, pelo que são classificados como irresponsáveis ou desinteressados; o não cumprimento a tempo das tarefas escolares recomendadas para fora da sala é motivo de penalização moral e social, rotulando o aluno como preguiçoso e desinteressado; em casa o olhar do aluno, ora sonolento ora desinteressado, sobre os trabalhos da escola, num período do dia em que os restantes membros da família já terminaram as suas obrigações profissionais e beneficiam de um tempo de lazer, ou pessoal ou familiar, demonstra o absoluto domínio do tempo escolar sobre as outras temporalidades; os testes cronometrados evidenciam a relação perversa entre a "[...] tirania do tempo e a banalização da aprendizagem” (Gimeno Sacristán, 2008, p. 20). Dentro da estrutura da escola, as condicionantes impostas pelo tempo são invariavelmente sentidas e, não raras vezes, opressoras. Alunos e professores são forçados a não respeitar os seus ritmos circadianos, não podendo comer ou descansar quando o corpo pede, condicionados que estão aos sincronismos impostos pelo ritmo escolar, pela hora de levantar, de almoçar ou de jan-

526 Educação \& Realidade, Porto Alegre, v. 41, n. 2, p. 515-531, abr./jun. 2016. 
tar, pela disciplina do corpo. Tão pouco a atividade letiva dos alunos é regulada de acordo com os seus momentos de maior capacidade de concentração e de raciocínio. São frequentemente forçados, pelo horário escolar, a concentrar-se em períodos do dia que lhes são biologicamente desfavoráveis, e a descansar quando o corpo está apto a trabalhar (Frada, 2009).

A opressão temporal sentida por alunos e professores, facilmente se extrapola para as mais diversas atividades profissionais e pessoais, permanentemente condicionadas pelo sincronismo horário, imposto por uma regulação cultural, no que Young (apud McLaren, 1996) apelida de imperialismo cultural, e que considera ser uma face da opressão. No limite, alunos, professores, um qualquer profissional, é simplesmente anulado na sua possibilidade de gerir o seu tempo, e assim definir os seus ritmos de execução das tarefas, ou, por outras palavras, não tem qualquer capacidade de decisão sobre a sua ação. O que configura numa ausência de poder, ou seja, uma outra forma de opressão, ainda na perspetiva de Young.

A compreensão do mundo e do papel que o relógio nela desempenha, reveladora da ação opressora do tempo, revela também as razões dessa opressão, que se podem afigurar como a génese do processo de mudança. "O grande problema está em como os oprimidos, que 'hospedam' o opressor em si, participarem da elaboração, como seres duplos, inautênticos, da pedagogia da sua libertação. Somente na medida em que se descubram 'hospedeiros' do opressor poderão contribuir para o partejamento de sua pedagogia libertadora" (Freire, 1987). O que o sincronismo horário não controla é a rapidez a que o tempo social escoa, podendo aqui residir a génese do processo de mudança. O ritmo biológico do ser humano não se substitui, nem é substituível pelos relógios, e a perceção da rapidez do tempo, ou seja, do tempo que o tempo demora a passar (Vieira, 2013), é condicionada por um conjunto de fatores independentes dos artefactos de medição sejam eles atómicos ou das efemérides. Smollan, Sayers e Matheny (2010, p. 32) lembram-nos que “[...] a forma como o tempo é vivido dependerá dos eventos e das situações que se sequenciarão no futuro”. A rapidez do tempo é, então, resultante da incorporação de factos pessoais e/ou sociais, muitas vezes relacionados com a intensidade com que se vive o período temporal presente, ou pelo significado dos acontecimentos que se projetam (Klein, 2007, p. 132), pelo que sem os relógios, a nossa apreciação do tempo, a par da sua duração, difere significativamente do que experienciamos quando o cronos regula o nosso quotidiano.

Daqui resulta a sensação, vivida por todos, de que o tempo nunca mais passa, ou, pelo contrário, a de que o tempo passou muito depressa. Isto porque a rapidez a que o tempo passa assenta em três pressupostos: 1 - que a ação demora tempo; 2 - que a ação tem de ter esse tempo; 3 que o tempo tem de estar disponível ${ }^{6}$. O tempo, aqui, é exclusivamente entendido como um recurso (Torre, 2006; 2007), disponível para que o 
A Hegemonia do Tempo Escolar

indivíduo possa realizar uma ação, como “[...] um recurso para as ações, e como tal pode ser direcionado para uma grande variedade destas. As mais óbvias das ações são estratégicas e instrumentalmente investidas de modo a obter algo" (Torre, 2006, p. 165). Para este autor, contrariamente ao tempo como um recurso, assumido como uma substância ou algo que se possui e com que se pode trabalhar, o tempo também pode ser entendido como um meio necessário ao desenvolvimento da ação, na qual se incorpora. "Por outras palavras, não é um agente (ou praticante), mas um paciente (ou portador) da ação” (Torre, 2006, p. 169). Os indivíduos que tomam o tempo como um meio tendem a falar da sua experiência, localizando-a numa malha de tempo que prende os acontecimentos.

Entre os vários fatores que condicionam a rapidez do tempo destacamos os que se podem relacionar com os níveis de desempenho de uma ação, o primeiro pressuposto referido. Em regra, quanto mais ocupado está um indivíduo com determinadas tarefas, e quanto mais exigentes estas são, ao nível da atenção e da concentração, mais depressa passa o tempo sentido se medido pelo tempo contado, ou seja, maior é a rapidez do tempo. O segundo pressuposto implica que a ação decorra no tempo, logo, este terá um papel ativo no desenrolar dos acontecimentos. A forma como a ação irá decorrer tem de estar articulada com a disponibilidade temporal do indivíduo para a realização da tarefa (em princípio far-se-á uma estimativa do tempo que a ação poderá vir a consumir) ${ }^{7}$. Por fim, o terceiro pressuposto - a necessidade de disponibilidade temporal - surge diretamente relacionado com o segundo. O tempo em sociedade, o tempo a que o indivíduo está sujeito, repetimos, está limitado ao sincronismo, sendo, portanto um recurso limitado por uma sucessão de acontecimentos medidos pelo relógio. Se, em teoria, existe sempre tempo para desempenhar uma tarefa, pode acontecer que este não seja um tempo livre, porque está delimitado por outras atividades síncronas. Então, a forma como o tempo é gerido, para que tarefas será aplicado, depende de critérios de periodização, que são multifatoriais e frequentemente extrínsecos ao próprio tempo.

Resumindo diríamos que, entendido o tempo como um recurso, o indivíduo toma o papel de agente responsável pela concretização da ação e o tempo assume-se como um ator, dado que influencia diretamente a ação, condicionando a tarefa a realizar e a forma como será realizada, ainda assim gerido pelo indivíduo, libertando-o da ação opressora imposta pelo sincronismo horário. Nas sociedades modernas e pós-modernas, o tempo é normalmente considerado escasso, daí a forma como é usado impor um conjunto de deliberações e de decisões, individuais e/ou coletivas, de otimização, assentes numa heterogeneidade de valores morais, económicos e políticos (Torre, 2007). Se, na ação docente, o tempo escolar for tomado como um meio, o aluno fica a ele subordinado, e o seu tempo de aprendizagem é secundarizado. $\mathrm{O}$ aluno que necessite de mais tempo para aprender que aquele que a escola lhe

528 Educação \& Realidade, Porto Alegre, v. 41, n. 2, p. 515-531, abr./jun. 2016. 
concede, será apelidado de lento, ou desinteressado, ou distraído, ou incapaz de aprender. Por outro lado, tomando-o como um recurso, poder-se-á permitir ao aluno que o gira em função das suas necessidades, em respeito pelo seu tempo de aprendizagem.

\section{Considerações Finais}

Ao concluirmos, salientamos que as concepções de tempo socialmente construídas foram adquirindo uma crescente importância e protagonismo, tanto na ação individual e coletiva, como nas relações humanas. O tempo tende a ser tomado como um bem maior incontestado, regulador e opressor. A escola, no seu currículo oculto, tem também a função de ensinar, talvez incutir no aluno, a necessidade de respeitar as regras temporais, preferencialmente de forma acrítica. Independentemente do percurso académico de cada indivíduo, a regulação temporal exercida pelas instituições escolares, com os seus ciclos e horários rígidos, tem repercussões nas temporalidades do aluno, da família e da sociedade. Da mesma maneira, o tempo escolar interfere com os ritmos biológicos dos indivíduos, com os seus tempos individuais, familiares e sociais. Os horários, sendo estruturais para as escolas e estruturantes na sua relação com o exterior, têm a capacidade de sincronizar os hábitos individuais e sociais das comunidades, impondo um ritmo diário também cíclico, comum a alunos, professores, e a todos os que com eles vivem. Uma escola com horários e calendários rígidos transmite uma perspetiva economicista de tempo, considera-o um bem escasso, como se houvesse uma qualquer entidade com a capacidade de julgar e condenar os que não o utilizam ajuizadamente. $O$ aluno começa a aprender regras e valores temporais no dia em que entra para a escola.

Recebido em 14 de abril de 2014 Aprovado em 03 de maio de 2015

\section{Notas}

1 No século XVII havia, naturalmente, diversos mecanismos de contar o tempo, como clepsidras e ampulhetas, mas nenhum tinha a precisão e reprodutibilidade necessária a um instrumento de medida de índole científica. Note-se que Galileu concluiu que o período de oscilação do pêndulo não dependia da massa suspensa, mas sim do comprimento do braço, ao que Cristian Huygens confirmou matematicamente a veracidade da afirmação, desde que o movimento do pêndulo fosse cicloidal.

2 As sete horas canónicas eram: matinas, momento de oração noturna; laudes, uma hora antes do Sol nascer; prima, a primeira hora do dia; terça, a meio da manhã; seta, ao meio-dia; nona, ao meio da tarde; as vésperas, marcando o pôr-do-sol e finalmente as completas, uma hora antes do deitar.

3 Atualmente consideram-se dois padrões para medir o tempo, o das efemérides e a frequência das oscilações atómicas, geralmente do Césio-133.

Educação \& Realidade, Porto Alegre, v. 41, n. 2, p. 515-531, abr./jun. 2016. 
4 Entende-se por dia natural o período de tempo que decorre entre o nascer e o pôr-do-sol, contido num dia sideral (tempo exato que a Terra demora a dar uma volta sobre o seu eixo de rotação).

5 Atendendo a que o tempo na sociedade atual tem características organizacionais estruturantes, cujas manifestações surgem como factos sociais - é uma estrutura condicionante e condicionada por outras estruturas sociais - registam-se implicações sobre o indivíduo, mas também sobre as estruturas sociais onde este se insere, com reflexo na definição dos valores socialmente aceites.

6 Por absurdo, negando-se estes três pressupostos, poderemos afirmar que sem ação a rapidez do tempo será nula. Não havendo ação não se consome tempo - a eternidade - e todo o tempo pessoal é tempo disponível.

$7 \mathrm{O}$ conceito de rapidez do tempo permite, numa primeira abordagem, avançar com uma explicação para o motivo pelo qual frequentemente as ações demoram mais tempo que o planeado. Quando o indivíduo faz um cálculo mental do tempo que uma tarefa demora, fá-lo com base no tempo contado, mesclado pelo tempo sentido, e como estará ocupado, o tempo passará com maior rapidez. Assim, quando é solicitado para fazer uma estimativa da duração, perguntando-se, por exemplo a que horas (em tempo contado) espera ter a atividade terminada, este tenderá a aproximá-la por defeito, referindo um tempo cronometrado inferior ao que efetivamente demorará.

\section{Referências}

ADAM, Barbara. Time. Cambridge: Polity Press, 2004.

BENEDITO, Escolano. La invencion del tiempo escolar. In: FERNANDES, Rogério; MIGNOT, Ana (Ed.). O Tempo na Escola. Porto: Profedições, 2008. P. 33-35.

BERGMANN, Werner. The Problem of Time in Sociology: An Overview of the Literature on the State of Theory and Research on the 'Sociology of Time', 10082. Time \& Society, Thousand Oaks, Sage Publications, v. 1, n. 1, p. 82-134, 1992. BRITES, Isabel. A centralidade de Vigiar e Punir. História da violência nas prosões, na obra de Michel Foucault. Revista Lusófona de Educação, Lisboa, v. 10 p. 167-184, 2007.

CLOUDSLEY-THOMPSON, John. Time Sense os Animals. In: FRASER, Julius Thomas (Ed.). The Voices of Time: a cooperative survey of man's views of time as expressed by the sciences and by the humanities. Amherst: The University of Massachusetts Press, 1981. P. 296-312.

D’AMBROSIO, Ubiratan. Literacy, Matheracy, and Technoracy: a trivium for today. Mathematical Thinking and Learning, v. 1, n. 2, p. 131-153, 1999.

D’AMBROSIO, Ubiratan. Etnomatemática: elo entre as tradições e a modernidade. Belo Horizonte: Autêntica, 2001.

FOUCAULT, Michel. Vigiar e Punir. 10. ed. Petrópolis: Editora Vozes, 1977.

FRADA, João. Biorritmos e Insucesso Escolar: algumas opiniões e reflexões. Portal de Saúde Pública, Portugal, 01 jul. 2009. Disponível em: <http://www. saudepublica.web.pt/TrabFrada/Biorritmos.htm\#1>. Acesso em: 04 set. 2010.

FRASER, Julius Thomas. Introduction. In: FRASER, Julius Thomas (Ed.). The Voices of Time: a cooperative survey of man's views of time as expressed by the sciences and by the humanities. Amherst: The University of Massachusetts Press, 1981. P. xvii-xlviii.

530 Educação \& Realidade, Porto Alegre, v. 41, n. 2, p. 515-531, abr./jun. 2016. 
FREIRE, Paulo. Pedagogia do Oprimido. 17. ed. Rio de Janeiro: Paz e Terra, 1987. Disponível em: <http://www.4shared.com/get/8898790/e87d147f/pedagogia oprimido.html>. Acesso em: 01 fev. 2014.

GALISON, Peter. Os Relógios de Einstein e os Mapas de Poincaré. Lisboa: Gradiva, 2005.

GIMENO SACRISTÁN, Jose. El valor del Tiempo en Educatión. Madrid: Ediciones Morata, 2008.

GLENNIE, Paul; THRIFT, Nigel. Shaping the Day: a History of timekeeping in England and Wales 1300-1800. Oxford: Oxford University Press, 2009.

HAMNER, Karl. Experimental Evidence for the Biological Clock. In: FRASES, Julius Thomas (Ed.). The Voices of Time: a cooperative survey of man's views of time as expressed by the scieces and by the humanities. Amherst: The University of Massachusetts Press, 1981. P. 281-296.

HARVEY, David. Justice, Nature and the Geography of Difference. 3. ed. Oxford: Blackwell Publishers, 1996.

KLEIN, Étienne. O Tempo. De Galileu a Einstein. Casal De Cambra: Caleidoscópio, 2007.

LANDES, David. A Revolução no Tempo. Lisboa: Gradiva, 2009.

McLAREN, Peter. Paulo Freire e o Primeiro Mundo. In: GADOTTI, Moacir (Ed.). Paulo Freire uma Biografia. São Paulo: Cortez, 1996. P. 587-589.

NOWOTNY, Helga. Time and Social Theory: toward a Social Theory of Time. Time \& Society, Thousand Oaks, Sage Publications, v. 1, n. 1, p. 421-454, 1992.

PÖPPEL, Ernest. Fronteiras da Consciência. Lisboa: Edições 70, 1985.

SMOLLAN, Roy; SAYERS, Janet; MATHENY, Jonathan. Emotional Responses to the Speed, Frequency and Timing of Organizational Change. Time \& Society, Thousand Oaks, Sage Publications, v. 19, n. 28, p. 28-53, 2010.

TORRE, Ramón Ramos. Time's Social Discourse. KronoScope, v. 6, n. 2, p. 231247, 2006.

TORRE, Ramón Ramos. Time's Social Metaphors: an empirical research. Time \& Society, Thousand Oaks, Sage Publications, v. 16, n. 157, p. 157-187, 2007.

TYACK, David; CUBAN, Larry. Tinkering toward Utopia: a Century of Public School Reform. London: Harvard University Press, 1995.

VIEIRA, Nuno. Os Tempos que o Tempo tem: o conhecimento trivium dos professores de matemática em período de mudança. 2013. (PhD). Departamento de Ciências da Educação, Universidade Lusófona de Humanidades e Tecnologias, Lisboa, 2013

WHITROW, Gerald James. What is Time? New York: Oxford University Press, 2003.

Nuno Vieira é professor na Universidade Lusófona de Humanidades e Tecnologias de Lisboa, e investigador do CeiED Centro de Estudos Interdisciplinares em Educação e Desenvolvimento). É Doutor em Educação pela Universidade Lusófona de Humanidades e Tecnologias, com a tese intitulada Os tempos que o tempo tem: o conhecimento trivium dos professores de matemática em período de mudança, orientado pelo Professor Emérito Ubiratan D'Ambroso.

E-mail: nuno.mcvieira@gmail.com

Educação \& Realidade, Porto Alegre, v. 41, n. 2, p. 515-531, abr./jun. 2016. 